\title{
THE EFFECT OF DIGITALIS ON THE NORMAL ELECTROCARDIOGRAM
}

\author{
BY
}

\author{
M. TILIAKOS
}

From the Cardiac Department of the London Hospital

Received October 22, 1952

With the advent of newer leads to the electrocardiogram it has become necessary to repeat the observations that have been made in the past on the cardiographic changes following digitalis administration in healthy subjects. The main object of this work has been to determine the lead or leads most susceptible to the effects of digitalis as well as the design of the deformity produced in the tracing. The need for the investigation has arisen from the common practice of giving digitalis to a patient considered to have heart disease before the electrocardiogram is recorded as part of a special examination. Confusion in diagnosis is specially likely if chest pain is included among the symptoms - a circumstance that allots more than ordinary importance to changes in the electrocardiogram.

Methods. The dosage of digitalis leaf was that customarily used in the continuous treatment of a patient needing it. It was, therefore, given in the first place as 2 grains $(0.13 \mathrm{~g}$.) daily and later increased to 3 grains $(0.2 \mathrm{~g}$.) daily. Rapid digitalization was not followed. Thirteen healthy medical students volunteered to take digitalis during a period of six to eight weeks when the total dosage was from 104 to 135 grains (6.9-9 g.). Digitalis was dispensed to each student when he attended the Cardiac Department to ensure accuracy in regard to the amount taken. A preliminary electrocardiogram was taken before the start of digitalis therapy and subsequent tracings were taken at intervals of four to ten days, and again after digitalis had been discontinued in order to discover the time it took the tracing to recover. The leads used included the four bipolar limb leads. I, II, III, and IIIR (lead III during deep inbreathing) and the three chest leads CR1, CR4, and CR7. The tracing was recorded by an Elmqvist machine with the subject in the reclining posture and a standardization of $1 \mathrm{~cm}$. from $1 \mathrm{mv}$. was strictly followed.

\section{RESULTS}

No toxic symptoms appeared in any of the students during the period of medication. In the analysis of the results information was specially sought in regard to four problems. First, the smallest dose of digitalis that produced noticeable changes in the electrocardiogram. Secondly, the amount of digitalis that produced changes that could only be told by comparison of two records; this information has no great value in practice when only a single electrocardiogram is available at the time, and most papers on the cardiographic effects of digitalis deal only with the findings obtained from a comparison of two tracings. Thirdly, the particular deformity that signalled the earliest digitalis effect. Fourthly, the period needed for such changes to disappear and allow a return of the tracing to its normal design.

The results will now be discussed under two heads dealing separately with the lesser and the more noticeable cardiographic changes.

\section{The Lesser Cardiographic Changes}

Changes in the electrocardiogram that could only be told by a comparison of the tracing with one recorded before the start of digitalis therapy are calssified as lesser ones. They include an 
alteration in the heart rate, heart rhythm, duration of the $\mathrm{P}-\mathrm{R}$ and $\mathrm{Q}-\mathrm{T}$ periods, form of the $\mathrm{P}$ wave, QRS complex, and T wave, and deformity of the S-T segment.

The heart rate. Many observers (Brams and Gaberman, 1931; Routier and Puddu, 1935) have reported a slowing of the heart rate by digitalis in most healthy subjects with sinus rhythm, but Pardee (1920) met this effect less frequently than changes in the height of the $T$ waves. Other workers (Lassen et al., 1937; Beers et al., 1951) reported a slower pulse rate in from one-third to two-thirds of their cases.

In my series a change in the heart rate less than 10 a minute was not considered to be significant. In 7 cases the rate was reduced by 10 or more beats a minute, in 5 cases by 15 or more, and in 2 cases by 20 or more. As a rule such a reduction in the rate was induced by upwards of 42 grains $(2 \cdot 8 \mathrm{~g}$.) of digitalis leaf given over a period of three weeks.

The heart rhythm. Although it is known that digitalis, especially in large doses, causes different forms of arrhythmia, these have seldom appeared in healthy subjects during digitalis medication (White and Sattler, 1916; Georgopoulos, 1934). Auricular premature beats, sino-auricular block, A-V dissociation, and paroxysmal auricular fibrillation are the commoner forms of abnormal rhythm to develop, but in the present series, when the subjects took some 135 grains $(9 \mathrm{~g}$.) within a period of 56 days, the rhythm remained normal in every case.

The $P-R$ period. Slight prolongation of the $\mathrm{P}-\mathrm{R}$ period by 0.01 to $0.04 \mathrm{sec}$. following digitalis given in daily doses of 15 to 60 grains (1-4 g.) for some days was present in 15 to 50 per cent of the cases reported by Cohn and Fraser (1913), Dieuaide et al. (1935), van Dyke and Li (1935), and Beers et al. (1951). McCulloch and Rupe (1921) found that lengthening of the P-R period in 9 out of 36 healthy children depended on the duration of the preceding diastole, being shorter after a long diastolic pause and longer after a short pause. Lassen et al. (1937) and Goldberger (1944) found lengthening of the P-R period in only a small number of their cases, while Cohn and Stewart (1929) found no change in six healthy subjects after a single dose of 12 to 15 grains $(0 \cdot 8-1$ g.). None of my 13 cases showed an increase in the $P-R$ period after taking upwards of 135 grains $(9 \mathrm{~g}$.) of digitalis over periods extending to 56 days.

The $Q-T$ period. Shortening of the Q-T period is a common digitalis effect; it occurred in each of the 13 cases. It was calculated as a ratio of the Q-T period determined by Bazzett's formula. This lesser cardiographic change appeared along with shortening of the $T$ wave, and it remained a little time after the return of the $T$ to normal. The average $Q-T$ ratio in my cases following digitalis was 0.80 as against 1.01 regarded as the average for healthy subjects. This finding agrees with the experience of other workers including Cheer and Dieuaide (1931), and Wiggers and Stimson (1927). White and Mudd (1929) found no alteration in the Q-T period in healthy subjects after digitalization when a dose of 30 to 45 grains $(2-3 \mathrm{~g}$.) was given in the course of seven to ten days.

The $P$ wave. The effects of digitalis on the $P$ wave of the electrocardiogram of healthy subjects have been variably described. Thus, unspecified changes were reported by Cohn and Fraser (1913), an increase in its size by Vacoel and Papapanajotou (1927), and a diminished amplitude by Routier and Puddu (1935). The $P$ wave remained unchanged in my cases and this experience tallies with that of many other workers.

The QRS complex. Although a change in the electrical axis or in the amplitude of the QRS complex has been noticed by some authors in healthy subjects following digitalis therapy (Georgopoulos, 1934, others have not seen such changes (Beers et al., 1951). No instance in the present series of 13 healthy students showed an alteration in either amplitude or duration of the QRS.

The $S-T$ segment and the $T$ wave. The more obvious deformity involving these components of the electrocardiogram is described under the more noticeable changes, and allusion here is only made to the earliest change that was only discernible by a comparison of the tracing with that recorded before digitalis therapy started (Fig. 1). When examined in this way depression of the $\mathrm{S}-\mathrm{T}$ and lowering of the $\mathrm{T}$ wave took place within one or two weeks on digitalis when a dose of 


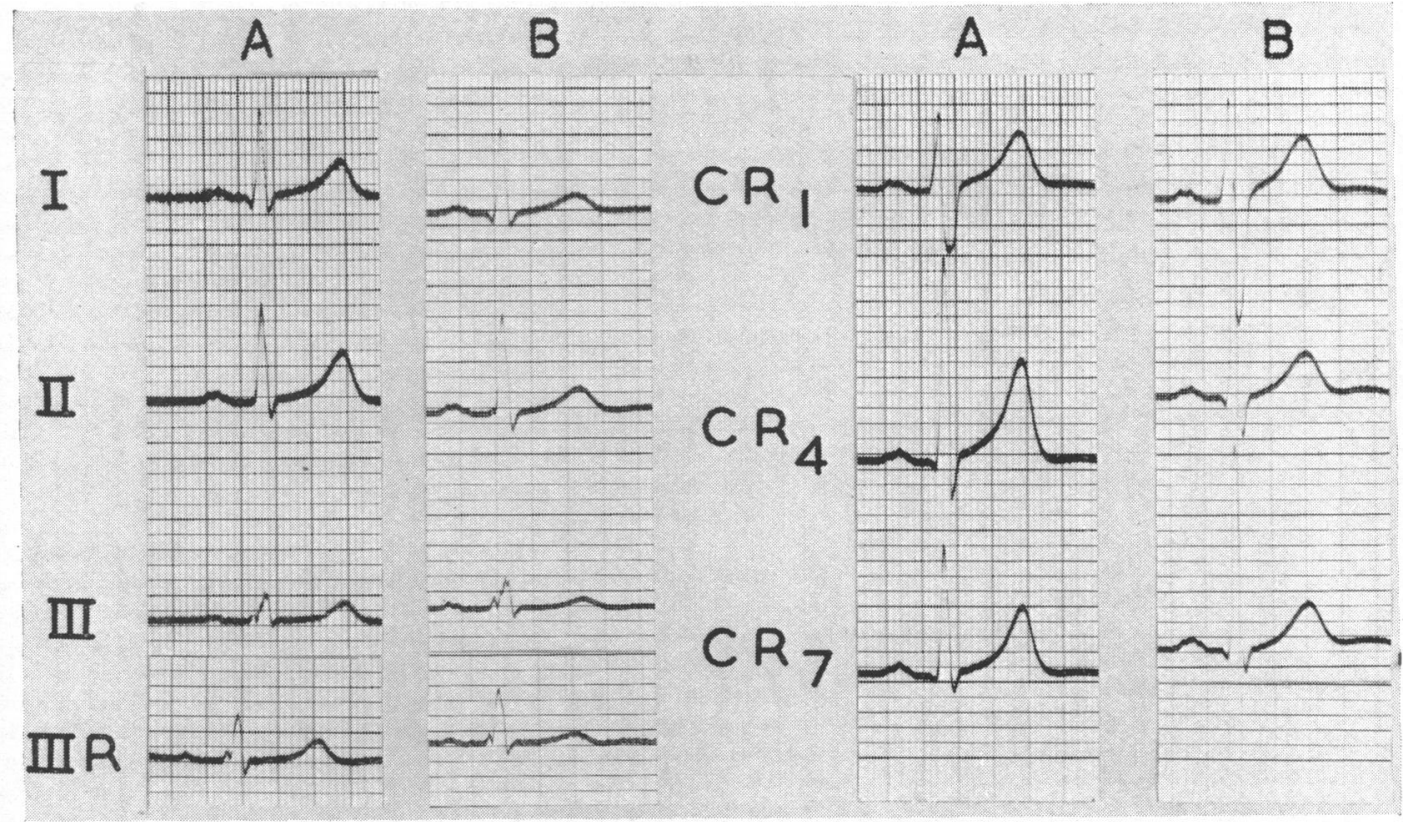

Fig. 1.- Lesser electrocardiographic changes following digitalis medication in a healthy subject (Case 7) who showed no more noticeable changes even after 107 grains $(7 \mathrm{~g}$.) of digitalis in 45 days. (A) is control tracing. (B) was taken after ingestion of 18 grains $(1.2 \mathrm{~g}$.) in 9 days; the Q-T period is reduced from 0.84 to 0.77 and the amplitude of the $\mathrm{T}$ wave is less than before in most leads.

from 14 to 30 grains (0.9-2 g.) had been given. A loss of height in the $T$ wave preceded depression of the S-T in 10 of the 13 cases; in the other three cases both changes appeared together. Like the major changes, the lesser ones were also seen to best advantage in lead IIIR. As digitalization proceeded the earlier relationship between deformity of the $S-T$ segment and the $T$ wave became reversed so that at the end of digitalization, changes in the $\mathrm{S}-\mathrm{T}$ were more noticeable than those in the $\mathrm{T}$ wave in all save three of the cases.

\section{The More Noticeable Cardiographic Changes}

It was Cohn and Fraser (1913) who first described depression of the S-T segment and of the $T$ wave following administration of 6 grains $(0.4 \mathrm{~g}$.) of the digitalis leaf daily for a week. Such changes appeared in lead III at the start and thereafter in lead II and in lead I (Cohn et al., 1915). The amount of digitalis necessary to cause deformity in the cardiogram has been estimated by various authors. Pardee (1920 and 1923) gave the effective dose as one-sixth or one-eighth of the therapeutic dose; Cohn and Stewart (1929) as about one-quarter of the lethal dose, and Bromer and Blumgart (1929) as half to two-thirds of the therapeutic dose. Marvin et al. (1925) found the cardiographic signs in 30 patients without heart disease from the administration of 22.5 grains $(1.5$ g.) per 100 pounds of body weight in the course of three days. Goldberger (1944) giving 30 grains $(2 \mathrm{~g}$.) of digitalis leaf in five days found that the cardiographic changes were constant irrespective of the pattern prevailing from any form of heart disease. Beers et al. (1951) obtained similar results and described the changes as preponderating in the left ventricular chest leads when the heart was in the transverse position and in the right ventricular leads when it was in the vertical position. Most authors have reported that actual inversion of the $T$ wave does not result from digitalis medication in healthy subjects (Irving and Feil, 1941), and Dearing et al. (1943) thought that such gross changes indicated a myocardial lesion. Scherf and Boyd (1948), however, have 
stated that inversion of the $T$ wave does not always depend on the presence of existing myocardial damage on the grounds that the same changes occur when there is disturbance of intraventricular conduction. Friedberg (1950) has written that if obvious inversion of the T wave appears during digitalization, it is likely that the heart is diseased, for in health the changes are confined to the S-T segment. Coelho (1932) studying the effects of toxic doses of digitalis in dogs, healthy people, and patients with heart disease, found inversion of the $T$ wave in the last, but never in the former two groups. Recently, Coelho and Borges (1952) re-examined the effects of digitalis on the electrocardiogram of healthy subjects and of patients suffering from different diseases which included gastric ulceration, bronchiectasis, Addison's disease, and avitaminosis; they reported that necropsy

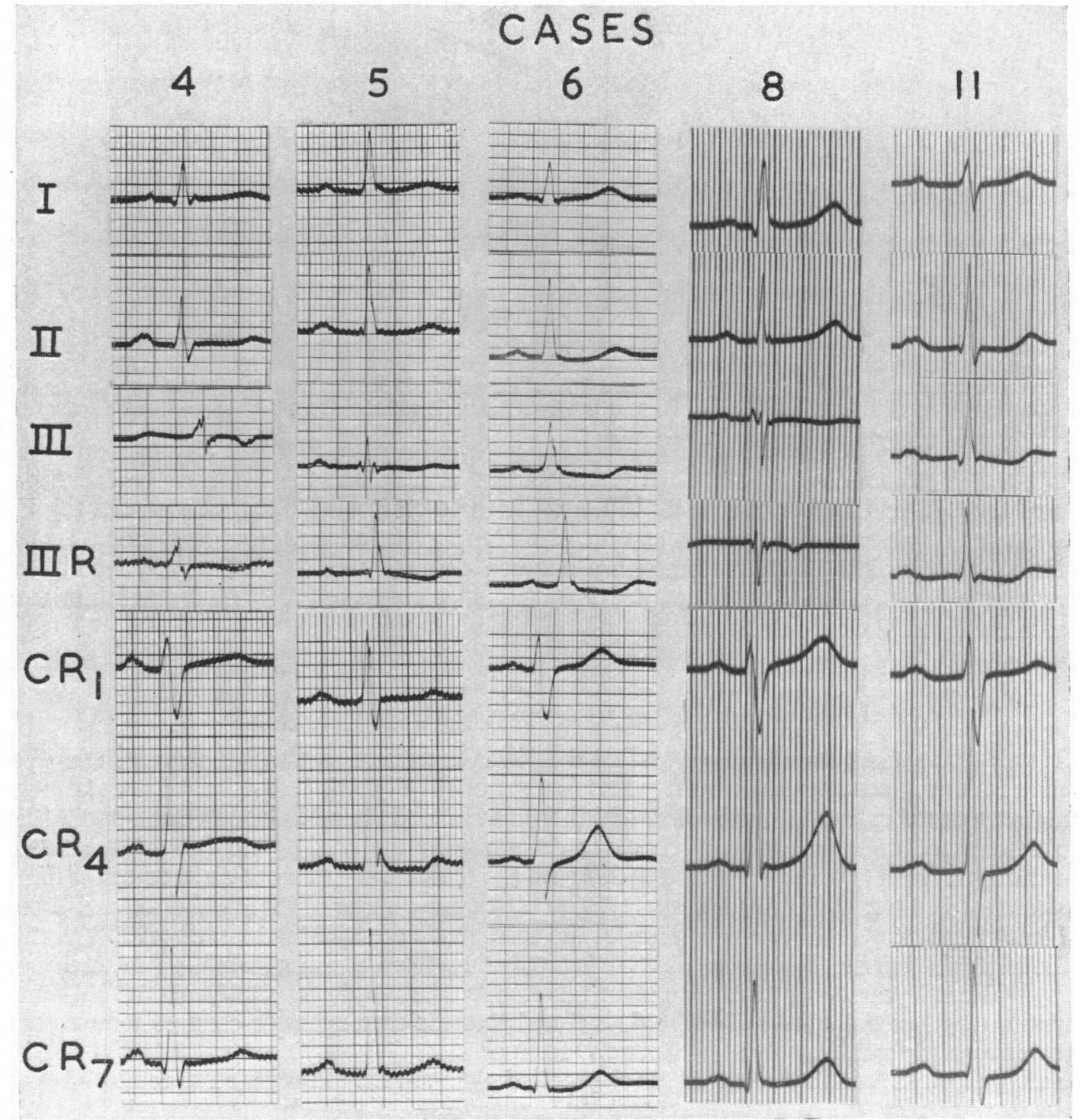

FIG. 2.-Noticeable electrocardiographic changes. following digitalis medication in healthy subjects after a dosage of 104 to 135 grains (6.9-9 g.) in 42 to 53 days. S-T depression in IIIR is present in all and often in other leads as well. Significant lowering of the $T$ wave is an additional feature of Cases 4 and 5. 
in those where the $\mathrm{T}$ wave had been inverted showed atheroma of the coronary arteries, and they even suggested that digitalis should be given in this way to test the efficiency of the myocardium.

In the present investigation the selection of the first tracing showing signs regarded as noticeable changes was made on the pretence that the cardiogram under review was from a patient with cardiac pain; on this premise an unequivocal abnormality in the $\mathrm{S}-\mathrm{T}$ segment or in the $\mathrm{T}$ wave was sought. Such changes were found in 11 of the 13 subjects during a period of digitalization which had lasted for six to eight weeks. In two students no obvious pathological signs could be identified in the single cardiogram (Fig. 1) after taking 106 grains of digitalis in 56 days in one, and 107 grains in $\mathbf{4 5}$ days in the other. No satisfactory explanation was found for the resistance of the heart to digitalis effects in these two instances; the one, aged 26, was tall and thin and the other, aged 24, was of average height and build. In the 11 cases showing changes, depression of the S-T segment was the deformity that first gave to the electrocardiogram its unequivocal abnormal appearance (Fig. 2). In eight the depression reached lower than the iso-electric level, while in the remaining three only a part of the S-T segment was depressed and not beyond the iso-electric line. The leads that showed such depression were considered and it was found that lead IIIR was the most sensitive lead in that it invariably showed the change either by itself or in combination with other leads, particularly III, II, and CR7; in three cases a depression of the S-T in III, remaining in IIIR, was the only significant change. In three students depression of the S-T segment was accompanied by an obvious lowering of the $T$ wave in all leads, but in none did this deformity appear as a lone sign or as the initial major sign of digitalization. In this series $\mathbf{S}-\mathbf{T}$ depression from digitalization appeared in both right and left chest leads, and the election of the side showing preponderant changes was not governed by the relative size of the $R$ and $S$ waves in CR1. Frank inversion of the $T$ wave or even a flat $T$ wave were not met with, but digitalis was discontinued in all 13 cases within eight weeks, and toxic doses were not employed.

These noticeable changes took place after the intake of from 105 to 135 grains $(7-9 \mathrm{~g}$.) of the digitalis leaf over a period of 42 to 56 days, an average dosage of 117 grains $(7.8 \mathrm{~g}$.$) in 50$ days.

The time taken for the significant changes to disappear from the cardiogram varied from 11 to 28 days, and the average period was 22 days.

\section{SUMmARY AND CONCLUSIONS}

Interest in the electrocardiographic changes produced by digitalis is not founded on the resultant changes in the heart muscle, but is directed solely to their recognition, so that they may not mislead in the diagnosis of a patient subject to cardiac pain who might at the time be taking digitalis. With this in mind digitalis was given to 13 healthy students and its effects watched in successive cardiograms.

Although lesser changes like shortening of the $Q-T$ period, lowering of the $T$ wave, and slight depression of the S-T segment appeared early and after the ingestion of 15 to 30 grains (1-2 g.) over a period of one to two weeks, they are of no great value in practice in that they are only discovered in a cardiogram when a control tracing is available for comparison. Such comparison showed that a loss of amplitude of the $\mathrm{T}$ wave usually preceded depression of the $\mathrm{S}-\mathrm{T}$ segment, but after a time the latter became the more prominent deformity.

The more noticeable changes that could be told from an inspection of a single cardiogram appeared in all except two cases after a dosage of from 105 to 135 grains (7-9 g.) of digitalis given during 42 to 56 days. These changes consisted of depression of the S-T segment, and lead IIIR was foremost in showing the deformity, as a rule in conjunction with other leads but sometimes by itself. In three cases $S-T$ depression was accompanied by obvious lowering of the $T$ wave, but this was never found as the only cardiographic evidence of digitalization.

S-T depression in the cardiogram of a patient without hypertensive or valvular heart disease who is subject to chest pain and has received digitalis medication is evidence of a myocardial injury from coronary arterial disease provided the dose of digitalis has not exceeded 70 grains (4.6 g.) in five weeks, or if such treatment has been discontinued for a period of four weeks. 
I wish to thank Dr. William Evans, Physician to the Cardiac Department of the London Hospital, for his help, and also the medical students who agreed to take part in the investigation.

\section{REFERENCES}

Beers, S. R., Regan, W., and Jensen, J. (1951). Amer. Heart J., 41, 114.

Brams, W. A., and Gaberman, P. (1931). Amer. Heart J., 6, 804.

Bromer, W. A., and Blumgart, L. H. (1929). J. Amer. med. Assoc., 92, 204.

Cheer, S. N., and Dieuaide, F. R. (1931). Chinese J. Physiol., 5, 217.

Coelho, E. (1932). Arch. Mal. Ceeur., 24, 746. and Borges, A. S. (1952). Estratto Clinica Latina, $2,1$.

Cohn, A. E., Fraser, R. F., and Jamieson, A. R. (1915). J. Exper. Med., 21, 593. and Fraser, F. R. (1913). Tr. Internat. Cong. Med. 1913, London 1914. Sect. VI, Medicine, Pt. II, 255.

_- and Stewart, H. J. (1929). J. Clin. Invest., 6, 53.

Dearing, H. W., Barnes, R. A., and Essex, J. H. (1943). Amer. Heart J., 25, 665.

Dieuaide, F. R., Tung, C. L., and Bien, C. W. (1935). J. Clin. Invest., 14, 725.

Friedberg, C. K. (1950). Disease of the Heart. Saunders, Philadelphia.

Georgopoulos, M. (1934). Deutsch. Arch. Klin. Med., 176, 348.

Goldberger, E. (1944). Amer. Heart J., 28, 370.

Grunbaum, F. (1931). Ztschr. Klin. Med., 116, 746.

Irving, M. L., and Feil, H. (1941). Amer. Heart J., 22, 683.

Lassen, K., Nuekirck, F., and Nielsen, N. (1937). Amer. Heart J., 13, 163.

McCulloch, H., and Rupe, A. W. (1921). Amer J. med. Sci., 162, 231.

Marvin, M. H., Pastor, B. R., and Carmichael, M. (1925). Arch. intern. Med., 35, 782.

Pardee, H. B. (1920). J. Amer. med. Assoc., 75, 1258. (1923). J. Amer. med. Assoc., 81, 186.

Routier, D., and Puddu, V. (1935). Arch. Mal. Caur., 28, 800.

Stewart, S. H., and Watson, R. (1938). Amer. Heart J., 15, 604.

Scherf, D., and Boyd, L. J. (1948). Clinical Electrocardiography. Heinemann, London.

Stewart, J. H., and Cohn, A. E. (1932). Jour. Clin. Investig., 11, 917.

Vacoel, J., and Papapanajotou, D. (1927). Arch. Mal. Caur., 20, 24.

van Dyke, H. B., and $\mathrm{Li}$, R. C. (1935). J. Clin. Invest., 14, 733.

White, P., and Mudd, S. (1929). J. Clin. Invest., 7, 387.

, and Sattler, R. (1916). J. Exper. Med., 23, 613.

Wiggers, C. J., and Stimson, B. (1927). J. Pharm. Exper. Therapy, 30, 251. 